\title{
Ag-loaded thermo-sensitive composite microgels for enhanced catalytic reduction of methylene blue
}

\author{
Luqman Ali Shah ${ }^{1} \cdot$ Murtaza Sayed $^{1} \cdot$ Muhammad Fayaz $^{2} \cdot$ Irum Bibi $^{2}$ • \\ Mohsan $\mathrm{Nawaz}^{2} \cdot$ Mohammad Siddiq $^{3}$
}

Received: 7 April 2017/Accepted: 21 July 2017 / Published online: 31 July 2017

(C) Springer International Publishing AG 2017

\begin{abstract}
In this work, we report the synthesis of composite system pNAC, composed of silver nanoparticles embedded in pure thermo-sensitive crosslinked polymer network of poly( $\mathrm{N}$-isopropylacrylamide-co-acrylamide) (pNA), using as a catalyst for the reduction of methylene blue (MB) dye by sodium borohydride $\left(\mathrm{NaBH}_{4}\right)$. The pNA was prepared by conventional free radical polymerization technique using sodium dodecyl sulfate as stabilizing agent, followed by in situ reduction of $\mathrm{AgNO}_{3}$ inside the polymer network by $\mathrm{NaBH}_{4}$ for the synthesis of composite systems pNACs. The synthesized pNA and pNACs were characterized by FTIR, dynamic light scattering, thermogravimetric analysis, scanning electron microscopy and UV-visible spectroscopy techniques. The materials were found sensitive toward temperature change of the medium. The entrapment ability of pNA toward different amounts of $\mathrm{AgNO}_{3}$ solution was studied, and effect of metal content on particle size of pNACs was analyzed. The pNACs were applied as a catalyst for the reduction of MB in which they exhibit high catalytic activity and reusability toward the reaction.
\end{abstract}

Luqman Ali Shah

Luqman_alisha@yahoo.com

Mohammad Siddiq

m_sidiq12@yahoo.com

Murtaza Sayed

murtazasayed_407@yahoo.com

1 National Centre of Excellence in Physical Chemistry, University of Peshawar, Peshawar 25120, Pakistan

2 Department of Chemistry, Hazara University Mansehra, Mansehra, Khyber Pakhtunkhwa, Pakistan

3 Department of Chemistry, Quaid-I-Azam University, Islamabad 45320, Pakistan
Keywords Composites · Thermo-sensitivity · Methylene blue $\cdot$ Catalytic activity $\cdot$ Reusability

\section{Introduction}

The discharge of both organic and inorganic pollutants in water bodies is the major cause of water pollution. The organic pollutants are mostly colored dyes widely used in textile, pharmaceutical, cosmetics, food and leather industries owing to their easy availability and low price [1]. But without proper treatment, these dyes contaminate water and cause very hazardous effects on aquatic life; that is., the microbial activity of aquatic organisms disturbs, which further reduces the transparency of water and mitigates photosynthesis, which results in the death of aquatic animals. For example, methylene blue (MB) is a heterocyclic aromatic cationic dye which in high concentration produces harmful effects in human beings, like tissue necrosis, vomiting, shock, mental confusion, anemia [2], when come in contact with their bodies. Therefore, the removal of MB dye from industrial effluents before discharge in water bodies is of prime importance, but due to their high stability and solubility in water the removal of this dye is very difficult and a challenging task for researchers working in environmental field. Furthermore, the colored form of MB cannot be biodegraded more easily as compared to its reduced colorless form. Several methods have been designed for the removal of MB and other organic pollutants from waste water such as adsorption desorption strategy [3-6], $\gamma$-irradiation [7], ozonation [8-10], photocatalysis [11-13], ion exchange [14], membrane separation [2], reverse or forward osmosis [15], electrochemical methods [16, 17], biochemical materials [18-20], but all these methods are either very expensive or cannot remove 
the pollutants completely. Chemical reduction method used to convert these dyes from toxic state to nontoxic or less toxic form is very easy and environmentally friendly, but the reduction of these dyes without catalyst takes much time. Therefore, a composite system composed of metal nanoparticles embedded in responsive polymer network have been designed and used as catalyst for reduction process. The entrapped metal nanoparticles act as catalyst while the polymer network used as stabilizing or sheltering agent for these particles in a controlled manner [21]. The beauty of these materials is its smart behavior; that is, we can tune the properties of metal nanoparticles by changing the properties of polymer network with external stimuli before or during the process of reduction, e.g., temperature [22-24], pH [25-27], ionic strength [28, 29]. In current years, many investigators have a great interest in the field of stimulus-responsive composite systems composed of continuous organic and dispersed inorganic phase [30] for different applications, e.g., drug delivery [31-33], sensors [34, 35], electrical [36], catalysis [37-39].

In this study, we have prepared composite systems of thermo-responsive polymer network of poly $(N$-isopropylacrylamide-co-acrylamide) embedded with different amounts of silver nanoparticles. The effect of $\mathrm{Ag}$ nanoparticles loading on particle size, thermo-sensitivity, catalytic performance and reusability toward the reduction of methylene blue (MB) was investigated. The thermoresponsive polymer network showed different capability toward absorption of metal ions from salt solution when present in different amounts.

\section{Experimental part}

\section{Materials}

$N$-isopropylacrylamide (NIPAM, purity 99\%), acrylamide (AAm, purity 99\%) and $N, N$-methylene bisacrylamide (BIS, purity 99\%) were purchased from Sigma-Aldrich and further purified by recrystallization before use. The initiator ammonium peroxodisulphate, the surfactant sodium dodecyl sulfate (SDS), nanoparticles source silver nitrate, reducing agent sodium borohydride and methylene blue (MB) dye were purchased from Scharlau and were used as received. Double distilled water (DDW) was used throughout the experimental process.

\section{Synthesis of pNA}

NIPAM (9 mmol, $1.02 \mathrm{~g})$, AAm (0.05 mmol, $0.036 \mathrm{~g})$, BIS (0.5 mmol, $0.08 \mathrm{~g})$ and SDS (0.02 g) were dissolved in $95 \mathrm{~mL}$ of deionized water in a three-neck flask equipped with a condenser, thermometer and nitrogen inlet to degas the reaction site. The flask was put in oil bath, and temperature was raised to $70{ }^{\circ} \mathrm{C}$, after that the mixture was injected with APS $(0.06 \mathrm{~g} / 5 \mathrm{~mL})$ solution to start free radical emulsion polymerization. The reaction was lift for $8 \mathrm{~h}$ to complete the polymerization process. After completion, the samples were purified, lyophilized and stored for further use. The synthesized pure poly $(N$-isopropylacrylamide-co-acrylamide) polymer network was coded as pNA.

\section{Synthesis of pNACs}

$12 \mathrm{mg}$ of pNA was dissolved in $40 \mathrm{~mL}$ of DDW in roundbottom flask fitted with nitrogen inlet to evacuate air and stirred until a homogenous mixture formed. The solution was further split into two equal parts, one half of the mixture was charged with $5 \mathrm{~mL} \mathrm{AgNO}_{3}(0.1 \mathrm{mmol}$, $0.017 \mathrm{~g} / \mathrm{L})$ and second half with $7 \mathrm{~mL} \mathrm{AgNO}_{3}(0.1 \mathrm{mmol}$, $0.017 \mathrm{~g} / \mathrm{L})$ solutions, diluted up to $30 \mathrm{~mL}$ and stirred for 3 h. $5 \mathrm{~mL} \mathrm{NaBH}_{4}(2.64 \mathrm{mmol}, 0.1 \mathrm{~g} / 5 \mathrm{~mL})$ solution was added dropwise to the reaction mixture for reduction of metal ions. The milky color of the solution was abruptly turned into yellowish green. After $4 \mathrm{~h}$, the samples were collected, lyophilized and stored for further use. Same procedure was followed for $8 \mathrm{~mL} \mathrm{AgNO}_{3}$ solution with the same concentration. The resulted composite systems synthesized with 5 and $8 \mathrm{~mL} \mathrm{AgNO}_{3}$ solutions were coded as pNAC5 and pNAC8, respectively.

\section{Catalytic activity and reusability of pNACs}

The catalytic activity of pNACs composite systems was checked for the reduction of methylene blue (MB) dye with $\mathrm{NaBH}_{4}$ in aqueous medium as a model reaction. For typical experiment $2 \mathrm{~mL}$ of $\mathrm{MB}$ solution $(0.1 \mathrm{mM})$ and $0.5 \mathrm{~mL}$ of $\mathrm{NaBH}_{4}$ solution $(30 \mathrm{mM})$ were added into a Quartz cell with path length of $1 \mathrm{~cm}$ and incubated for a while, and $0.1 \mathrm{~mL}$ of pNAC solution with catalyst amount (pNAC5, $5.9 \times 10^{-3} \mathrm{mg}$ of $\mathrm{Ag}$ and pNAC7, $8.4 \times 10^{-3} \mathrm{mg}$ of $\left.\mathrm{Ag}\right)$ was introduced into cell. The UV-visible spectroscopy was used to monitor the progress of reaction. The pNACs were regenerated by ultracentrifugation after the completion of reaction and reused again in the same experimental conditions for five consecutive cycles.

\section{Characterization techniques}

FTIR spectra were performed on a NEXUX-470 spectrometer. The average hydrodynamic diameter of both pure (pNA) and composite (pNACs) was measured on a Malvern Autosizer 4700 instrument. Scanning electron microscope (SEM, JEOL-JSM 7500F, Japan) with electron acceleration voltage $20 \mathrm{kV}$ was used for determination of 
size and surface morphology of the synthesized materials. The ultraviolet visible absorption spectra for pNACs and catalytic reduction of methylene blue (MB) were taken on a PerkinElmer Lambda 750 UV/Vis/NIR spectrometer.

\section{Results and discussion}

\section{Characterization of pNA and pNACs}

Temperature-sensitive pNA was synthesized with free radical emulsion polymerization. The composites pNACs were synthesized by in situ reduction of $\mathrm{AgNO}_{3}$ solution by $\mathrm{NaBH}_{4}$. The FTIR spectra shown in Fig. 1 revealed all the possible functional group peaks and confirmed the formation of pNA and the existing of $\mathrm{Ag}$ nanoparticles in pNACs. The major peaks obtained in the FTIR spectrum of pNA are 3296, 2972, 1652, 1259, 986 and $691 \mathrm{~cm}^{-1}$. The broad peak at $3296 \mathrm{~cm}^{-1}$ is assigned to the stretching mode of $-\mathrm{NH}$ functional group in the gel. The peak at $2972 \mathrm{~cm}^{-1}$ is attributed to asymmetric stretching vibration of $-\mathrm{CH}_{2}-$ group, the peak at $1652 \mathrm{~cm}^{-1}$ is due to carbonyl group of amide functionality, while the peaks at 1259, 986 and $691 \mathrm{~cm}^{-1}$ are the characteristic peaks for $-\mathrm{CO}$ (str.), $-\mathrm{CN}$ (str.) and $-\mathrm{NH}$ bending, respectively. The same FTIR spectra were obtained for pNACs with slight shifting in the peak positions, which indicates the interaction of entrapped metal nanoparticles in polymer composites; for example, the peak at 1652 was shifted to $1640 \mathrm{~cm}^{-1}$ and the absorption frequency at 1259,986 and $691 \mathrm{~cm}^{-1}$ was shifted to 1237,1010 and $727 \mathrm{~cm}^{-1}$, respectively. The FTIR analysis suggests that carbonyl and amines functionality have a greater tendency to retain metal nanoparticles inside the composites.

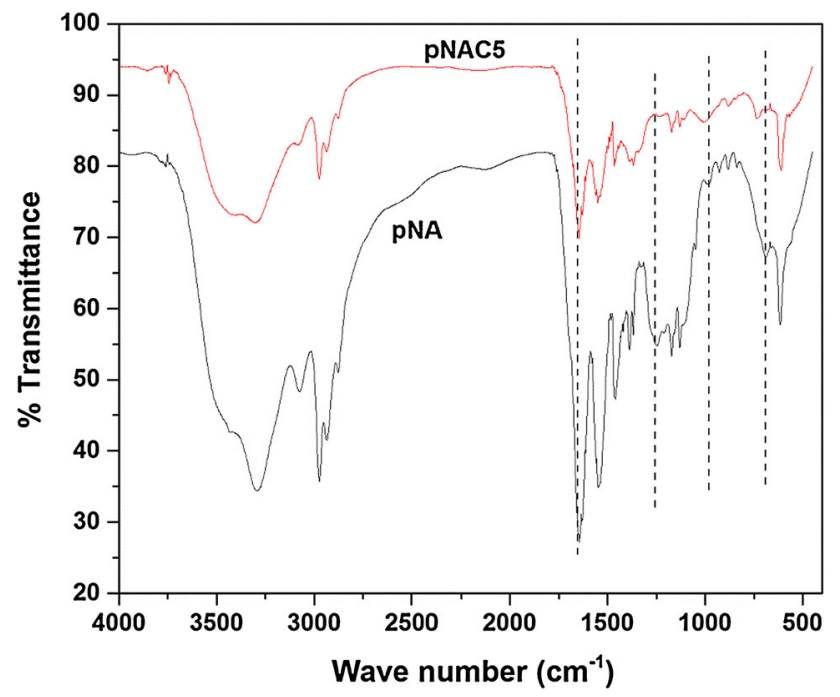

Fig. 1 FTIR spectra for pNA and pNAC5
The entrapped metal content was further studied by thermo-gravimetric analysis (TGA), and results are explored in Fig. 2. The thermogram of pNA shows about $95.4 \%$ weight loss at $736^{\circ} \mathrm{C}$, which is reduced to 54.7 and $46.7 \%$ for pNAC5 and pNAC7, respectively, indicating that pNAC7 accommodates more metal content (48.7\%) as compared to pNAC5 which entrapped $40.8 \%$ metal content. This increase in metal content is due to the availability of metal salt in high amount to pNA.

\section{Size dependence of pNA and pNACs on temperature}

The mean hydrodynamic diameter of pure pNA and composite pNACs was investigated using dynamic light scattering (DLS). The materials show responsive behavior toward change in temperature of the corresponding medium due to the presence of thermo-sensitive segment PNIPAm in its structure. Temperature-induced volume phase transition (VPT) of the materials was measured at a scattering angle of $90^{\circ}$, in terms of hydrodynamic diameter $\left(D_{\mathrm{h}}\right)$. Both pure (without metal particles) and hybrid (metal-loaded) synthesized materials show clear three steps shifting in their size with application of temperature as shown in Fig. 3. At low temperature (below $31^{\circ} \mathrm{C}$ ), $D_{\mathrm{h}}$ of the particles is high because of the strong hydrophilic interactions which lead to the penetration of water molecules inside the polymer network and result in the swelling of the particles to a maximum value (swollen state). The increase in temperature shifted gradually the $D_{\mathrm{h}}$ of the particles to smaller value (shrunken state) because of the shrinkage of PNIPAm chains, which produced a remarkable VPT. The size reduction with temperature increase is because of the increase in random thermal motion of water molecules which diminish the hydrophilic forces and expel water molecules from polymer network. Figure 3a shows

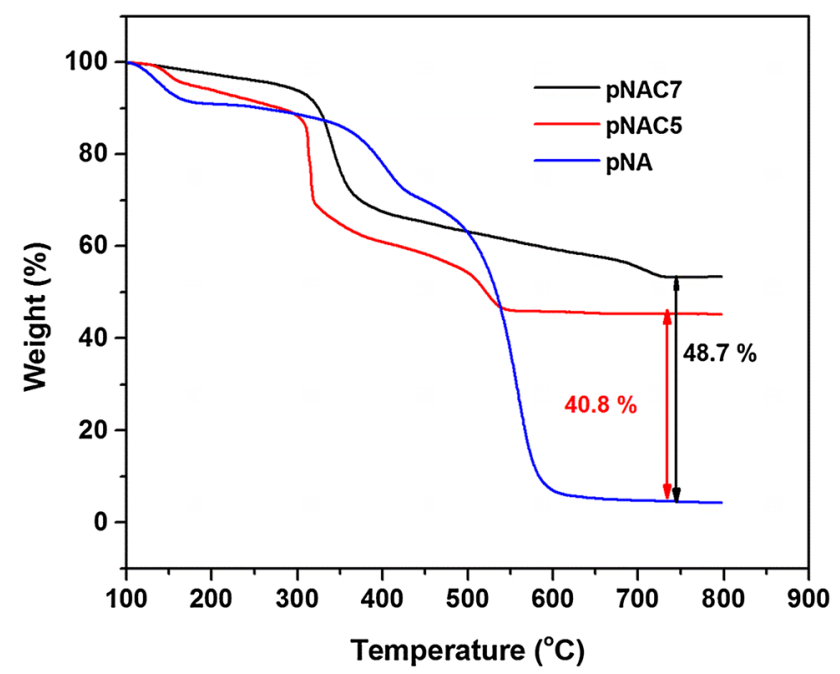

Fig. 2 TGA curves for pNA, pNAC5 and pNAC7 

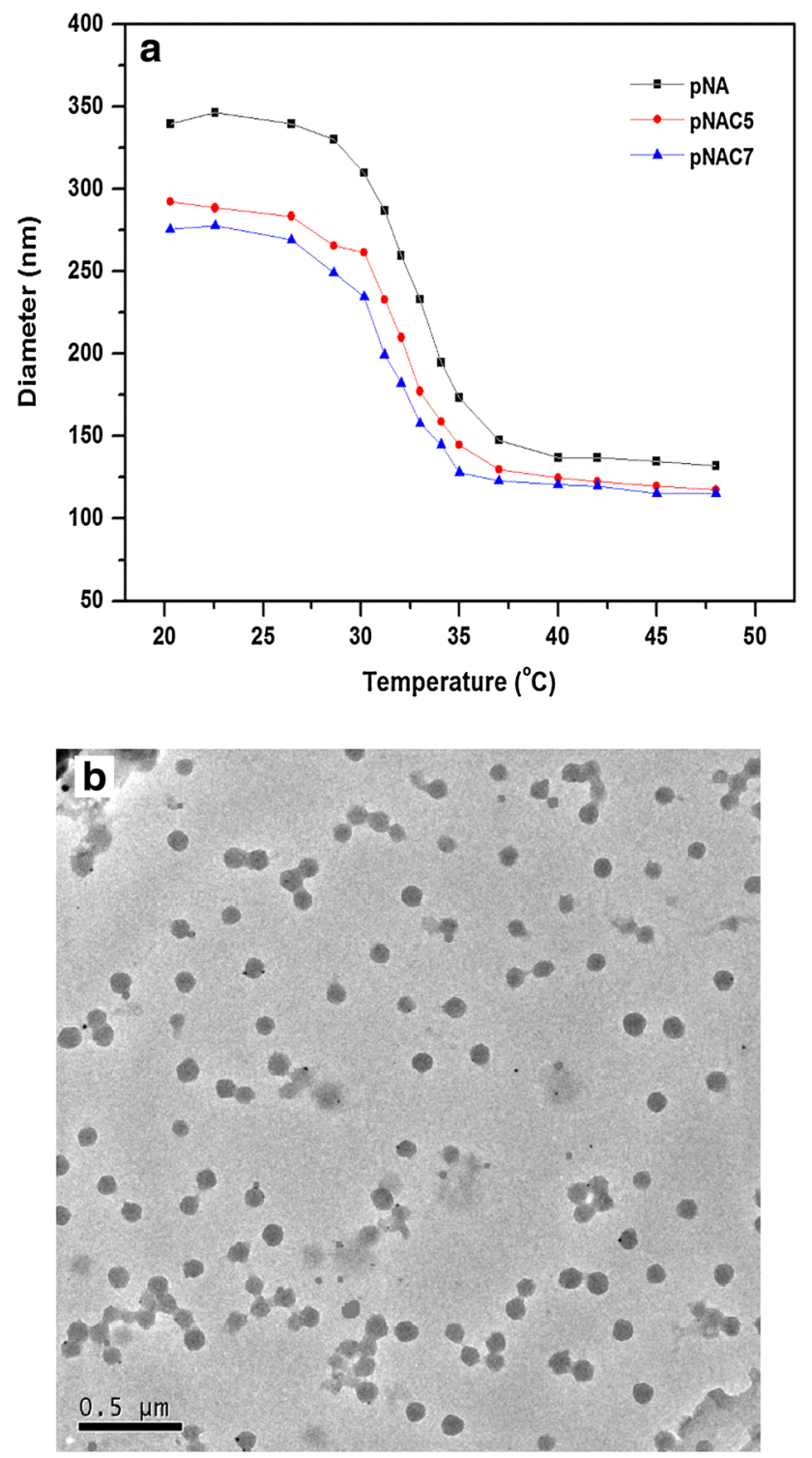

Fig. 3 a Temperature dependence of the average hydrodynamic diameter measured at scattering angle of $90^{\circ}$. b SEM image of pNA

that $D_{\mathrm{h}}$ of pNAC5 and pNAC7 (in both swollen and collapsed states) is less than pNA, because metal nanoparticles act as physical cross-linking or complexing agents for NIPAM and AAm and therefore decrease the particle size and degree of collapsing. The materials show a complete reversible swelling and de-swelling transition behavior from one state to another. The temperature-induced VPT enable us to change the surface environment of the entrapped metal nanoparticles, which can be employed for tuning optical and catalytic applications. The size of pNA was also confirmed by scanning electron microscopy (SEM), and the image is given in Fig. 3b. The size of pNA calculated by SEM is $\sim 95 \mathrm{~nm}$ which is lesser than the size obtained from dynamic light scattering (DLS), because the
DLS considers the samples in solution form, whereas SEM calculated size of the particles in dry state.

\section{Temperature-responsive UV-visible absorption property of pNACs}

The UV-visible spectra of pNACs were obtained at a temperature range of $20-50{ }^{\circ} \mathrm{C}$ in aqueous solution, as shown in Fig. 4. The spectra indicate a main dipole absorption peak at 395-408 $\mathrm{nm}$ (indicates the presence of Ag nanoparticles), which arises because of the positive and negative charge shifting to one end and the other end, respectively, on the particle surface, giving the particle itself a dipole moment that reverses the sign at same frequency as the incident light [40]. Surface polarization and change in local refractive index around the metal nanoparticles are responsible to determine the intensity and
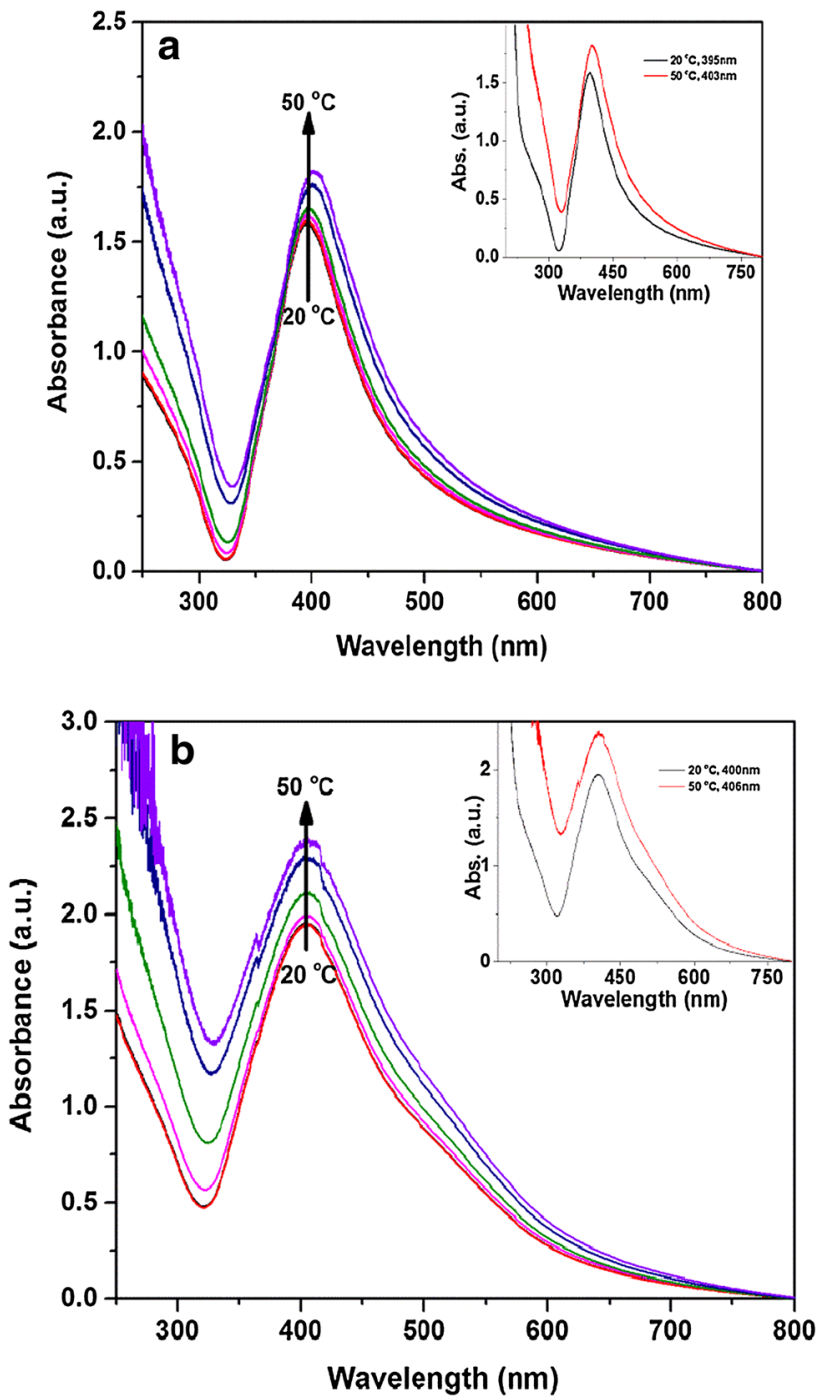

Fig. 4 Temperature-responsive UV-visible spectra for a pNAC5 and b pNAC7 
Fig. 5 Schematic representation of LangmuirHinshelwood reduction mechanism on the surface of $\mathrm{Ag}$ nanoparticles

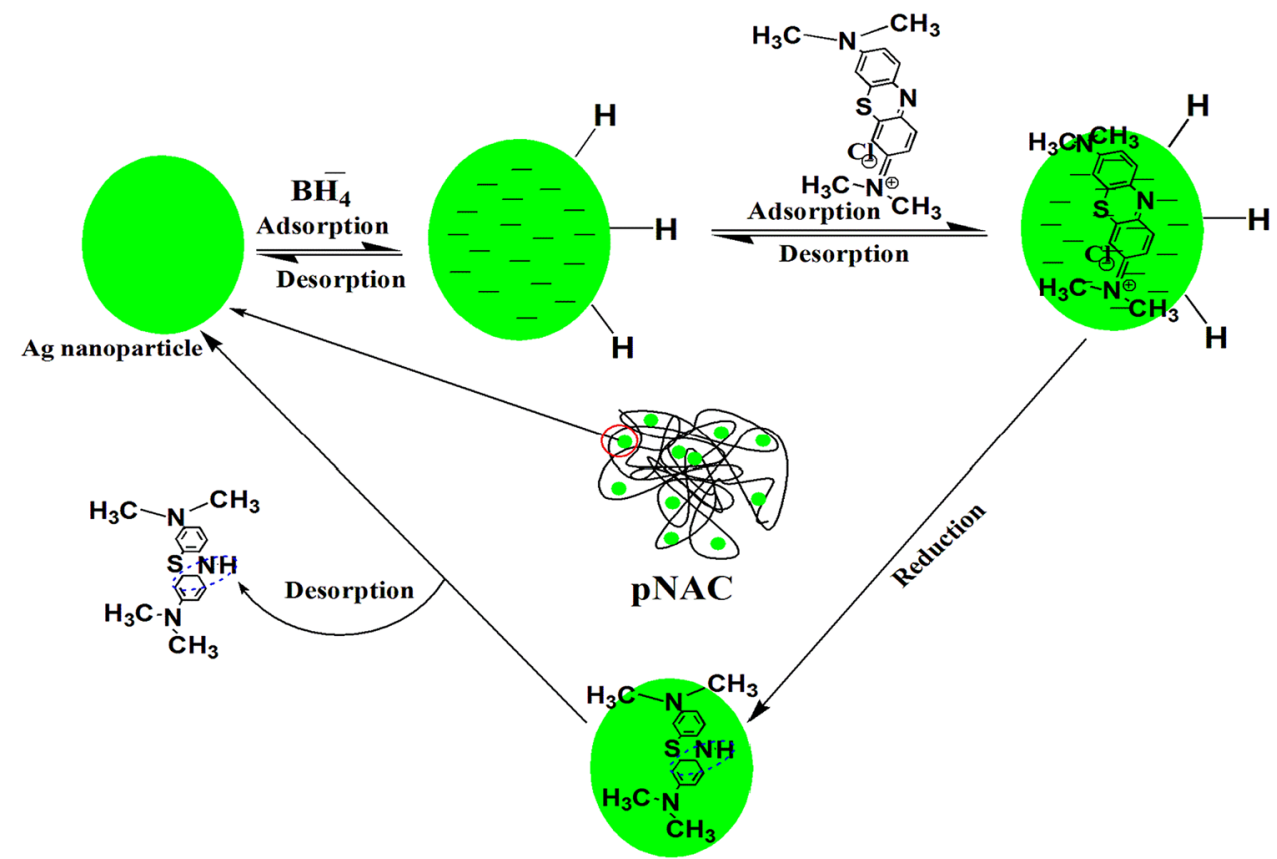

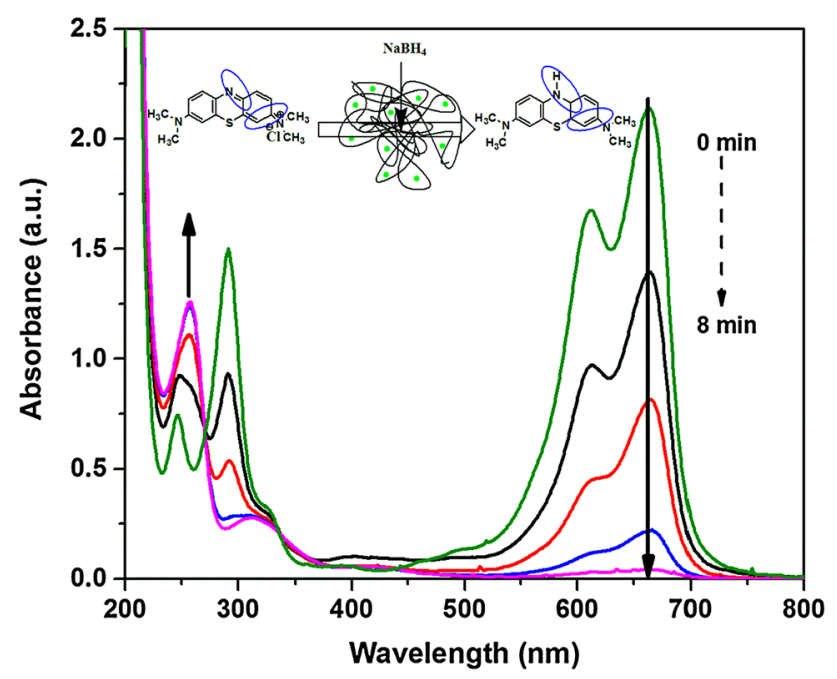

Fig. 6 UV-visible spectra for reduction of $\mathrm{MB}$ by $\mathrm{NaBH} 4$ in the presence of pNAC5

position of absorption peak for the given metals. In our synthesized composite materials, the refractive index of water and medium surrounding the $\mathrm{Ag}$ nanoparticles is same at below volume phase transition temperature (VPTT), which changes with the variation in temperature of the medium and causes a shift in absorption peak of $\mathrm{Ag}$ nanoparticles. Figure 4a, b shows the temperature-responsive UV-visible spectra for pNACs, when temperature of the medium changes from 20 to $50{ }^{\circ} \mathrm{C}$, a redshift, and an increase in absorption intensity was observed. This variation is due to the transition of polymer network from swollen state (at $20{ }^{\circ} \mathrm{C}$ ) to collapsed state (at $50{ }^{\circ} \mathrm{C}$ ), which

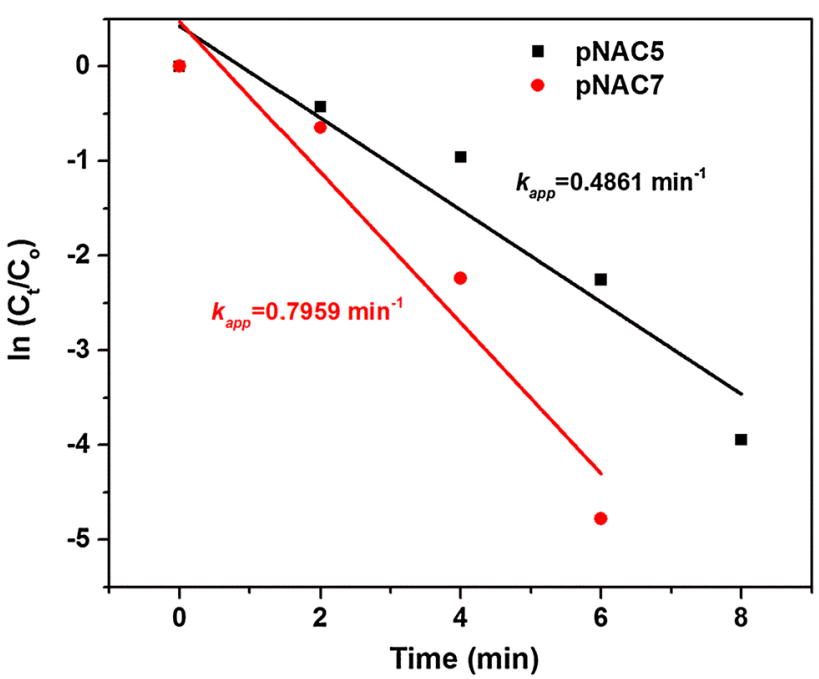

Fig. 7 Plot of $\ln \left(C_{\mathrm{t}} / C_{\mathrm{o}}\right)$ as a function of time for the catalytic reduction of $\mathrm{MB}$ by $\mathrm{NaBH}_{4}$ in the presence of pNAC5 and pNAC7 as a catalysts

causes a change in local refractive index around the $\mathrm{Ag}$ nanoparticles to that of the solvent refractive index and produces a redshift. An increase in absorption intensity can also be attributed to increase in concentration to volume ratio of $\mathrm{Ag}$ nanoparticles, because of the shrinking of polymer network with temperature. The absorption peaks for pNAC5 and pNAC7 were appeared at 395 and $400 \mathrm{~nm}$, respectively, at $20^{\circ} \mathrm{C}$, which were shifted to 403 and $406 \mathrm{~nm}$ at $50{ }^{\circ} \mathrm{C}$, respectively, as shown in the insets of Fig. 4. The increase wavelength of pNAC7 compared to pNAC5 is due to their large encapsulation capacity of $\mathrm{Ag}$ 


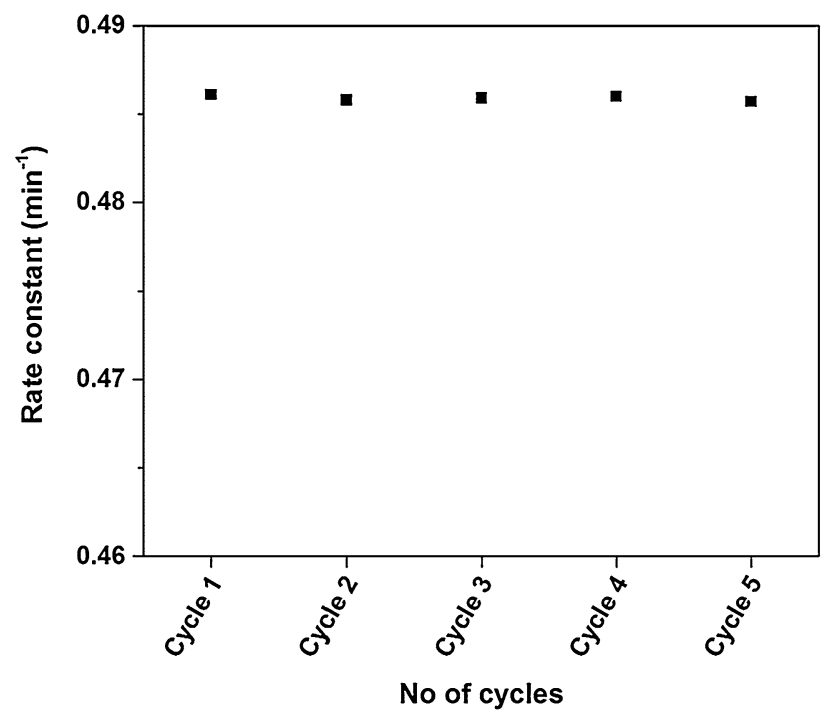

Fig. 8 Reusability of pNAC5 as catalyst for the reduction of MB by $\mathrm{NaBH}_{4}$

nanoparticles in pNA [41], as discussed earlier in TGA results.

\section{Catalytic performance and reusability of pNACs}

The catalytic behavior of synthesized pNACs was elaborated for reduction of methylene blue (MB) by $\mathrm{NaBH}_{4}$ in aqueous solution at room temperature. The reduction reaction occurs on the surface of $\mathrm{Ag}$ nanoparticles as shown schematically in Fig. 5 based on classical Langmuir-Hinshelwood model [21]. Initially, borohydride ions adsorbed on the $\mathrm{Ag}$ nanoparticles surface and leave hydrogen on its surface, followed by adsorption of MB; both the reactions are reversible in nature. The reduction reaction takes place and colored $\mathrm{MB}$ converted into colorless one, which desorbed from the surface of $\mathrm{Ag}$ nanoparticles and regenerated the naked surface for further reactants. MB gives a strong absorption peak $\left(\lambda_{\max }\right)$ at $663 \mathrm{~nm}$ due to chromophore in its structure; the addition of $\mathrm{NaBH}_{4}$ alone produced no change in its color and absorption intensity for a long time. With the addition of small amount of pNACs, the blue color of the reaction mixture disappeared completely, which indicated the successful reduction of MB dye. The progress of reaction was controlled by UV-visible spectroscopy. As given in Fig. 6, the maximum absorption peak at $663 \mathrm{~nm}$ reduces gradually and a new peak at $\sim 250 \mathrm{~nm}$ appears representing the reduction of azo group. A linear trend was obtained (shown in Fig. 7) by plotting $\ln \left(C_{\mathrm{t}} / C_{\mathrm{o}}\right)$ against time, where $C_{\mathrm{t}}$ is the concentration of $\mathrm{MB}$ at any time " $t$ " and $C_{\mathrm{o}}$ is its initial concentration. This indicates that the reaction follows pseudo-first-order kinetics with respect to $\mathrm{MB}$, as the concentration of $\mathrm{NaBH}_{4}$ is very high. The apparent rate constant $\left(k_{\text {app }}\right)$ was calculated from the slope of the linear curve. The $k_{\text {app }}$ values were 0.4861 and $0.7959 \mathrm{~min}^{-1}$ for pNAC5 and pNAC7, respectively, as shown in Fig. 7. The $k_{\text {app }}$ value for pNAC7 is greater than that of the pNAC5, because of the greater encapsulation capability of metal content by pNAC7 compared to pNAC5, and acting as an effective catalyst for the reduction of MB dye. The catalysts were separated by centrifugation ( $8000 \mathrm{rpm}, 5 \mathrm{~min}$ ) and reused for the same catalytic reduction reaction. The catalytic performance of pNACs was found by calculating $k_{\text {app }}$ values for five consecutive cycles and was found almost same shown in Fig. 8, which indicates clearly that pNACs show enhanced catalytic activity and reusability in the reduction of MB.

\section{Conclusion}

In summary, pNACs composite systems with thermo-responsive pNA template embedded with Ag nanoparticles were prepared successfully by in situ chemical reduction of $\mathrm{AgNO}_{3}$ by $\mathrm{NaBH}_{4}$. The amount of $\mathrm{Ag}$ nanoparticles was controlled by using different amounts of $\mathrm{AgNO}_{3}$ solution. The thermo-responsive behavior of pNA and pNACs was checked by DLS and UV-visible spectroscopy, respectively. The synthesized composite materials were checked for their catalytic performance in the reduction of MB by $\mathrm{NaBH}_{4}$. Considering their catalytic activity and reusability, it was found that pNACs have potential application in catalysis and can be used in other reduction processes.

Acknowledgement Dr. Luqman Ali Shah gratefully acknowledges Higher Education Commission (HEC) of Pakistan for financial support under the project No: 21-718/SRGP/R\&D/HEC/2016.

\section{References}

1. Mittal H, Kumar V, Ray SS (2016) Adsorption of methyl violet from aqueous solution using gum xanthan $/ \mathrm{Fe}_{3} \mathrm{O}_{4}$ based nanocomposite hydrogel. Int J Biol Macromol 89:1-11

2. Soniya M, Muthuraman G (2015) Comparative study between liquid-liquid extraction and bulk liquid membrane for the removal and recovery of methylene blue from wastewater. J Ind Eng Chem 30:266-273

3. Alqadami AA, Naushad M, Abdalla MA, Khan MR, Alothman $\mathrm{ZA}$ (2016) Adsorptive removal of toxic dye using $\mathrm{Fe}_{3} \mathrm{O}_{4}-\mathrm{TSC}$ nanocomposite: equilibrium, kinetic, and thermodynamic studies. J Chem Eng Data 61(11):3806-3813

4. Daneshvar E, Vazirzadeh A, Niazi A, Kousha M, Naushad M, Bhatnagar A (2017) Desorption of methylene blue dye from brown macroalga: effects of operating parameters, isotherm study and kinetic modeling. J Clean Prod 152:443-453

5. Albadarin AB, Collins MN, Naushad M, Shirazian S, Walker G, Mangwandi C (2017) Activated lignin-chitosan extruded blends for efficient adsorption of methylene blue. Chem Eng J 307:264-272 
6. Alqadami AA, Naushad M, Abdalla MA, Ahamad T, ALOthman ZA, Alshehri SM, Ghfar AA (2017) Efficient removal of toxic metal ions from wastewater using a recyclable nanocomposite: a study of adsorption parameters and interaction mechanism. J Clean Prod 156:426-436

7. Sayed M, Khan JA, Shah LA, Shah NS, Khan HM, Rehman F, Khan AR, Khan AM (2016) Degradation of quinolone antibiotic, norfloxacin, in aqueous solution using gamma-ray irradiation. Environ Sci Pollut Res 23(13):13155-13168

8. Wu J, Ma L, Chen Y, Cheng Y, Liu Y, Zha X (2016) Catalytic ozonation of organic pollutants from bio-treated dyeing and finishing wastewater using recycled waste iron shavings as a catalyst: removal and pathways. Water Res 92:140-148

9. Hu E, Shang S, X-m Tao, Jiang S, K-l Chiu (2016) Regeneration and reuse of highly polluting textile dyeing effluents through catalytic ozonation with carbon aerogel catalysts. J Clean Prod 137:1055-1065

10. Rezaei F, Moussavi G, Bakhtiari AR, Yamini Y (2016) Toluene removal from waste air stream by the catalytic ozonation process with MgO/GAC composite as catalyst. J Hazard Mater 306:348-358

11. Sharma G, ALOthman ZA, Kumar A, Sharma S, Ponnusamy SK, Naushad M (2017) Fabrication and characterization of a nanocomposite hydrogel for combined photocatalytic degradation of a mixture of malachite green and fast green dye. Nanotechnol Environ Eng 2(1):4

12. Sayed M, Fu P, Shah LA, Khan HM, Nisar J, Ismail M, Zhang P (2015) VUV-photocatalytic degradation of bezafibrate by hydrothermally synthesized enhanced 001 facets $\mathrm{TiO}_{2} / \mathrm{Ti}$ film. J Phys Chem A 120(1):118-127

13. Sayed M, Shah LA, Khan JA, Shah NS, Nisar J, Khan HM, Zhang P, Khan AR (2016) Efficient photocatalytic degradation of norfloxacin in aqueous media by hydrothermally synthesized immobilized $\mathrm{TiO}_{2} / \mathrm{Ti}$ films with exposed 001 facets. J Phys Chem A 120(50):9916-9931

14. Gupta V, Pathania D, Singh P, Kumar A, Rathore B (2014) Adsorptional removal of methylene blue by guar gum-cerium(IV) tungstate hybrid cationic exchanger. Carbohydr Polym 101:684-691

15. Hartanto Y, Yun S, Jin B, Dai S (2015) Functionalized thermoresponsive microgels for high performance forward osmosis desalination. Water Res 70:385-393

16. Brillas E, Martínez-Huitle CA (2015) Decontamination of wastewaters containing synthetic organic dyes by electrochemical methods. An updated review. Appl Catal B 166:603-643

17. Turcanu A, Bechtold $\mathrm{T}$ (2017) Cathodic decolourisation of reactive dyes in model effluents released from textile dyeing. J Clean Prod 142:1397-1405

18. Sharma G, Naushad M, Pathania D, Mittal A, El-Desoky G (2015) Modification of Hibiscus cannabinus fiber by graft copolymerization: application for dye removal. Desalin Water Treat 54(11):3114-3121

19. Pathania D, Katwal R, Sharma G, Naushad M, Khan MR, Ala'a H (2016) Novel guar gum $/ \mathrm{Al}_{2} \mathrm{O}_{3}$ nanocomposite as an effective photocatalyst for the degradation of malachite green dye. Int $\mathbf{J}$ Biol Macromol 87:366-374

20. Pathania D, Gupta D, Alaa H, Sharma G, Kumar A, Naushad M, Ahamad T, Alshehri SM (2016) Photocatalytic degradation of highly toxic dyes using chitosan-g-poly (acrylamide)/ZnS in presence of solar irradiation. J Photochem Photobiol A 329:61-68

21. Hervés P, Pérez-Lorenzo M, Liz-Marzán LM, Dzubiella J, Lu Y, Ballauff M (2012) Catalysis by metallic nanoparticles in aqueous solution: model reactions. Chem Soc Rev 41(17):5577-5587

22. Yue M, Hoshino Y, Ohshiro Y, Imamura K, Miura Y (2014) Temperature-responsive microgel films as reversible carbon dioxide absorbents in wet environment. Angew Chem Int Ed 126(10):2692-2695
23. Hou L, Wu P (2014) The effect of added gold nanoparticles on the volume phase transition behavior for PVCL-based microgels. RSC Adv 4(74):39231-39241

24. Zhou X, Zhou Y, Nie J, Ji Z, Xu J, Zhang X, Du B (2014) Thermosensitive ionic microgels via surfactant-free emulsion copolymerization and in situ quaternization cross-linking. ACS Appl Mater Interfaces 6(6):4498-4513

25. Sakthivel M, Franklin D, Sudarsan S, Chitra G, Guhanathan S (2017) Investigation on Au-nano incorporated $\mathrm{pH}$-sensitive (itaconic acid/acrylic acid/triethylene glycol) based polymeric biocompatible hydrogels. Mater Sci Eng C 75:517-523

26. Ye X, Li X, Shen Y, Chang G, Yang J, Gu Z (2017) Self-healing $\mathrm{pH}$-sensitive cytosine-and guanosine-modified hyaluronic acid hydrogels via hydrogen bonding. Polymer 108:348-360

27. Naeem H, Farooqi ZH, Shah LA, Siddiq M (2012) Synthesis and characterization of $p$ (NIPAM-AA-AAm) microgels for tuning of optical properties of silver nanoparticles. J Polym Res 19(9):9950

28. Jia X, Wang K, Wang J, Hu Y, Shen L, Zhu J (2016) Full-color photonic hydrogels for $\mathrm{pH}$ and ionic strength sensing. Eur Polym J 83:60-66

29. Zhu F, Lin XY, Wu ZL, Cheng L, Yin J, Song Y, Qian J, Zheng Q (2016) Processing tough supramolecular hydrogels with tunable strength of polyion complex. Polymer 95:9-17

30. Karg M (2016) Functional materials design through hydrogel encapsulation of inorganic nanoparticles: recent developments and challenges. Macromol Chem Phys 217(2):242-255

31. Wu W, Shen J, Banerjee P, Zhou S (2010) Chitosan-based responsive hybrid nanogels for integration of optical $\mathrm{pH}$-sensing, tumor cell imaging and controlled drug delivery. Biomaterials 31(32):8371-8381

32. Yan B, Boyer J-C, Habault D, Branda NR, Zhao Y (2012) Near infrared light triggered release of biomacromolecules from hydrogels loaded with upconversion nanoparticles. J Am Chem Soc 134(40): 16558-16561

33. Kumar VA, Shi S, Wang BK, Li I-C, Jalan AA, Sarkar B, Wickremasinghe NC, Hartgerink JD (2015) Drug-triggered and cross-linked self-assembling nanofibrous hydrogels. J Am Chem Soc 137(14):4823

34. Buenger D, Topuz F, Groll J (2012) Hydrogels in sensing applications. Prog Polym Sci 37(12):1678-1719

35. Han D-M, Zhang QM, Serpe MJ (2015) Poly( $N$-isopropylacrylamide)-co-(acrylic acid) microgel/Ag nanoparticle hybrids for the colorimetric sensing of $\mathrm{H}_{2} \mathrm{O}_{2}$. Nanoscale 7(6):2784-2789

36. Wünnemann $P$, Noyong $M$, Kreuels $K$, Brüx R, Gordiichuk $P$, van Rijn P, Plamper FA, Simon U, Böker A (2016) Microstructured hydrogel templates for the formation of conductive gold nanowire arrays. Macromol Rapid Commun 37(17):1446-1452

37. Tang Y, Wu T, Hu B, Yang Q, Liu L, Yu B, Ding Y, Ye S (2015) Synthesis of thermo-and $\mathrm{pH}$-responsive Ag nanoparticle-embedded hybrid microgels and their catalytic activity in methylene blue reduction. Mater Chem Phys 149:460-466

38. Shah LA, Chen W, Siddiq M, Hu J, Dong A, Yang D (2015) Thermal and $\mathrm{pH}$ dual responsive copolymer and silver nanoparticle composite for catalytic application. Chin J Chem 33(4):467-472

39. Shah LA, Haleem A, Sayed M, Siddiq M (2016) Synthesis of sensitive hybrid polymer microgels for catalytic reduction of organic pollutants. J Environ Chem Eng 4(3):3492-3497

40. Wu W, Zhou T, Berliner A, Banerjee P, Zhou S (2010) Smart core-shell hybrid nanogels with Ag nanoparticle core for cancer cell imaging and gel shell for pH-regulated drug delivery. Chem Mater 22(6): 1966-1976

41. Bhui DK, Bar H, Sarkar P, Sahoo GP, De SP, Misra A (2009) Synthesis and UV-Vis spectroscopic study of silver nanoparticles in aqueous SDS solution. J Mol Liq 145(1):33-37 